\title{
ЯЗЫКОВАЯ ИГРА С ИМЕНАМИ СОБСТВЕННЫМИ В ГАЗЕТНОМ ЗАГОЛОВКЕ
}

\author{
Ольга Ермачкова
}

\section{LANGUAGE GAME WITH PROPER NOUNS IN THE NEWSPAPER HEADLINE}

\author{
Olga lermachkova
}

\begin{abstract}
Резюме: Статья посвящена феномену языковой игры в публицистическом заголовке. Особое внимание уделяется именам собственным (антропонимам, топонимам и т.д.), которые становятся материалом для образования игровых заголовков в печатных СМИ. Цель статьи - определить наиболее продуктивный разряд имен собственных, а также самый востребованный прием для образования игрового заголовка в российском печатном издании «Коммерсантъ» за 2019-2020 гг.
\end{abstract}

Ключевые слова: языковая игра, заголовок, имя собственное, антропоним, топоним.

Abstract: The article is devoted to the phenomenon of language game in journalistic title. Particular attention is paid to proper names (anthroponyms, toponyms, etc.), which have become the material for the formation of game titles in the print media. The purpose of the article is to determine the most productive class of proper nouns, as well as the most popular method for creating a game headline in the Russian printed edition "Kommersant" for 2019-2020.

Key words: language game, headline, proper noun, anthroponym, toponym.

DOI: $10.14712 / 9788076032088.1$

\section{Введение}

Живя в постмодернистское время, нам постоянно приходится искать нестандартные решения и новые подходы к языку. Почетное место в различных дискурсах XXI века заняла языковая игра, явившись результатом демократизации общества, средством выражения максимальной экспрессии, данью языковой моде. Термин «языковая игра» появился в 1985 году благодаря философу Л. Витгенштейну, который языковой игрой называл любой вид деятельности, связанный с языком. Однако, закрепиться данному термину было суждено в лингвистике в более узком формате. Под языковой игрой в языкознании понимают: «отклонение от языковой нормы», «нарушение нормативного языкового канона», «опрокидывание языкового стереотипа» (Гридина 2002, 26), «сознательное нарушение правил» (Булыгина, Шмелев 1997, 450), «намеренную неправильность» (Санников 1999, 23), «намеренные авторские аномалии» (Апресян 1995). Часто в языковой игре видят проявление творческого потенциала человека: «Языковая игра (в максимально широком понимании термина) - это нетрадиционное, неканоническое использование языка, это творчество в языке, это ориентация на скрытые эстетические возможности языкового знака» (Норман 1987, 168). Т. А. Гридина отмечает, что такие игры возможны при наличии лингвокреативного мышления «способности опознать игровой код общения» (Гридина 1996, 10). 
В контексте данного исследования мы будем считать языковой игрой проявление творческой сущности автора в языке, основанное на сознательном отходе от нормы с целью проведения эксперимента с формой, желая «поиграть» с реципиентом (читателем), проверить его «лингвокультурологические способности».

В наше время языковая игра занимает главенствующее место в разговорном, публицистическом, рекламном, политическом, юмористическом дискурсах, художественной литературе, дискурсе Интернета и телевидения, выполняя ряд функций: комическую, прагматическую, манипулятивную, оценочную, релаксирующую, эстетическую, языкотворческую, характерологическую, защитную, маскировочную, компрессивную, эмотивную, развлекательную, выразительную, акцентирующую, вербующую и др. На наш взгляд, наиболее востребованной и примечательной языковая игра является в рекламном и публицистическом дискурсах. Эти сферы используют данный прием в наиболее заметных частях, которыми являются газетные заголовки и рекламные слоганы. Поэтому именно заголовки основной объект нашего исследования в данной статье. Источником материала послужило публицистическое издание «Коммерсантъ» (далее К) за 2019-2020 гг.

\section{Имя собственное и его классификации}

Окружающий мир предстает перед человеком как пространство различных названий. В действительности каждый существующий объект обладает своим собственным наименованием. Как отмечает российский ономатолог А.В. Суперанская, «наряду с именами нарицательными в любом языке имеются имена собственные, которые служат для называния отдельного единичного предмета и позволяют отличать их от множества подобных им предметов» (Суперанская 2012, 9).

«Собственные имена в узком смысле этого слова - это географические $и$ астрономические названия и имена людей и животных. Это - лексически ограниченный и медленно пополняемый круг слов-названий, присваиваемых или присвоенных одному предмету» (Русская грамматика 1982, 460).

По мнению многих лингвистов, основным критерием для разграничения имен нарицательных (ИН) и имен собственных (ИС) является цель их применения: первые используются для классификации и обобщения, вторые - для индивидуализации объекта (Белецкий 1972; Хвесько 2009; Мерзлякова 2015). Особенностью ИС является написание сбольшой буквы, а также особая парадигма склонения.

Вопрос о классификации имен собственных является одним из самых сложных и неоднозначных. Одной из самых подробных является классификация А.В. Суперанской, согласно которой ИС можно разделить на: 1. антропонимы (личные имена, фамилии, отчества); 2. зоонимы (клички животных); 3. фитонимы (названия растений); 4. топонимы (названия географических объектов); 5. космонимы (названия зон Вселенной); 6. астронимы (названия небесных тел); 7. фалеронимы (награды); 8. хрононимы (названия исторических периодов, событий); 9. документонимы; 10. теонимы (имена богов); 11. демонимы (имена духов); 12. хрематонимы (индивидуальные имена неодушевленных предметов); 13. фиктонимы (имена в художественных произведениях) (Суперанская 1974, 17).

Типологии последних десятилетий более узкие. Так классификация Е.А. Нахимовой включает следующие группы онимов в прецедентных текстах: 1) антропонимы; 2) топонимы; 3) названия художественных или иных произведений; 4) хрононимы; 5) названия объектов 
бизнеса; 6) названия кораблей; 7) клички животных (Нахимова 2011, 85-99). В нашем исследовании мы будем придерживаться данной классификации.

\section{Имена собственные на газетной полосе}

Особую группу исследований занимают работы по изучению имен собственных в газетных текстах. Ономастическая лексика является важной частью публицистического текста, «выполняя свою первичную функцию индивидуализации, ономастические единицы не только останавливают внимание на индивидуальном объекте, но и устанавливают тождество называемых единичных объектов окружающего мира. Формируя антропонимическое пространство газетно-журнального текста, онимы могут выступать в двух ипостасях: в качестве информативных и в качестве социально-оценочных языковых средств» (Буркова 2010).

Ономастическая лексика способна оказывать эмоционально-оценочное воздействие, так как она накапливает тезаурусную информацию об именуемом объекте, поэтому она становится материалом для языковых игр в заголовках публицистических изданий.

\section{Языковая игра с топонимами на газетной полосе}

Функционируя как единицы языковой системы, топонимы идентифицируют и индивидуализируют объекты, накапливая и сохраняя комплекс сведений о человеческой деятельности. Классическим определением данного понятия является дефиниция А. В. Суперанской, которая под ним понимает «собственное имя любого географического объекта, выделяемого человеком в качестве самостоятельной единицы» (Суперанская 1984, 174-175).

Топонимы являются важным компонентом публицистического стиля, так как они документально точно локализуют действие во времени и пространстве. Публицистический текст - продукт анализа реальных событий, который «воспроизводит преимущественно объективное пространство с помощью лексических и контекстных средств» (Пушкарева 2012, 104).

Использование топонимов в игровых заголовках - яркая черта современной публицистики. Топоним в заголовке - акцент читателя на том, о какой стране/области/городе идет речь в статье. Чаще всего топонимы наблюдаются в рубриках «Мир», «Мировая экономика», «Зарубежные новости», «Политика» и т.п.

Наиболее многочисленными являются хоронимы (названия любых территорий, областей, районов, стран) на газетной полосе.

Рассмотрим языковые игры с хоронимом Китай:

Не по Китай меня (К, 19.2.2020) - статья о том, что Россия оставляет гражданам КНР только транзитный въезд. Отмечаем каламбур, основанный на омофонном сходстве с выражением не покидай меня.

Китай отсюда! (К, 18.02.2020) - статья о страхе общения с китайцами во время пандемии. Заголовок построен по аналогии с выражением Канай отсюда! Канать - идти, передвигаться. Данное выражение восходит к киноцитате из к/ «Джентльмены удачи» - $A$ ну, канай отсюда, редиска!

Китайская отчаянная церемония (К, 3.12.2019) - статья о В. Путине на открытии «Силы Сибири». Заголовок создан по аналогии с выражением китайская чайная церемония.

Тяжело в учении - легко в Китае (К, 19.9.2019) - статья об изучении китайского языка. Топонимом Китай был заменен компонент русской пословицы/крылатого выражения А.В. 
Суворова Тяжело в учении - легко в бою.

Последнее всекитайское предупреждение (К, 25.5.2020) - статья о закрытии «гонконгского вопроса». В заглавии обыгрывается идиома, означающая бесплодные угрозы «на словах» - последнее китайское предупреждение.

Хороним Ливия присутствует в заголовках:

Пересечение параллельных Ливий (К, 14.2.2020) - статья о двух делегациях из одной страны. Заголовок построен по аналогии со словосочетанием пересечение двух линий, основываясь на фонетическом подобии.

Ливия от Сирии недалеко падает (К, 13.01.2020) - статья о встрече политиков. Топонимы Ливия и Сирия заменяют компоненты пословицы Яблоко от яблони недалеко падает.

Ливийпульская четверка (К, 13.1.2020) - заголовок статьи о визите представителей обеих сторон ливийского конфликта. Окказиональный заголовок обыгрывает прецедентное выражение ливерпульская четверка - группа «Битлз».

Языковые игры с хоронимом Иран представлены в заголовках:

Ирано радоваться (К, 10.01.2020) - заголовок статьи об отношениях Тегерана и Вашингтона. Наблюдаем каламбур, основанный на омофонном сходстве И рано радоваться Ирано радоваться. Обыгрывается название страны Иран.

Еще одну языковую игру с этим хоронимом отмечаем в заголовке Изыраненная добыча (К, 23.04.2019) - статья о нефти Ирана. Заголовок образован по аналогии с выражением израненная добыча.

Языковые игры с хоронимом Польша фиксируем в следующих заголовках:

Владимир Путин распалялся все Польше и Польше (К, 25.12.2019) - статья о восстановлении исторической справедливости. Заголовок обыгрывает фонетическое сходство наречия больше и название страны Польша в Д.п. (ср. распалялся все больше и больше).

То же фонетическое сходство обыгрывается еще в одном заголовке Ставка Польще чем жизнь (К, 23.12.2019) - статья о новой Мюнхенской речи президента. Заголовок апеллирует к названию польского сериала «Ставка больше, чем жизнь».

В заголовке Дания преследования (К, 21.11.2019) - о встрече сборной России с Данией, отмечаем аналогию с выражением мания преследования. Автор обыграл фонетическое сходство хоронима Дания и слова мания.

С хоронимом Дания также связан заголовок Принцип датский (K, 31.10.2019) о Северном потоке 2, в котором есть отсылка к герою произведения У. Шекспира (ср. прини датский).

Окказиональное обыгрывание хоронима Грузия находим в заголовке Перезагрузия Украины (К, 15.5.2019) - статья о политике М. Саакашвили. Заголовок построен на соединении слов перезагрузка и Грузия, путем усечения первого.

Языковая игра с хоронимом Украина обнаружена в заголовке Реджеп Эрдоган вдоволь наукраинился (К, 4.2.2020) - о визите турецкого президента. Окказиональный глагол образован на базе хоронима по аналогии с глаголами, обозначающими окончание действия (напр., наговорился).

Хороним США в игровой форме представлен в заглавии Соединенные штаммы Америки (К, 21.11.2019) - статья о том, как Россия видит США.

Спорная область Кашмир обыгрывается в заголовках:

В кашмирном сне не присниться (К, 15.8.2019) - о кризисе в отношениях Дели и Исламабада. Заголовок создан по аналогии с выражением в кошмарном сне не присниться, 
основываясь на фонетическом подобии;

Третья кашмировая война (К, 19.02.2019) - об Индии и Пакистане (ср. Третья мировая война).

Окказиональное краткое прилагательное, созданное на базе хоронима Донбасс отмечаем в заголовке Особо донбасен (К, 14.8.2019) - о переговорах по Донбассу. Заголовок также апеллирует к названию фильма «Особо опасен».

Окказиональное существительное на базе названия республики Абхазия фиксируем В заголовке Абхазование новой власти ( $К, 14.1 .2020)$ - статья об Абхазии.

Фонетическое сходство названия исторической области Израиля - Иудеи и слова идея обыграно в заглавии статьи Дональда Трампа посетила гениальная Иудея (К, 29.1.2020) о планах по Палестине.

Названия федеральной земли Германии (Бавария) и одноименного футбольного клуба обыгрываются в заголовке Мюнхенская Базария (К, 15.2.2020) - о конференции по безопасности.

Не менее частотны на газетной полосе языковые игры с астионимами (названиями городов):

Bom вам и братиславно (К, 2.9.2019) - о победе команды. Обыгрывается название города Братислава. Окказиональное наречие создано по аналогии с выражением вот и славно.

Политические будапешки (K, 3.06.2020) - статья о том, что Киев предлагает вместо минских договоренностей провести будапештские. Окказиональное заглавие образовано слиянием астионима Будапешт и слова пешки.

Кредит-батор (К, 4.9.2019) - о кредите Монголии. В заголовке наблюдаем игру с названием столицы Монголии - Улан-батором.

Мы в такие шагали в Дели (К, 3.9.2019) - о Восточном экономическом форуме. Заголовок отсылает к строчке из песни «Синяя птица» группы «Машина времени» - Мы в такие шагали дали. Языковая игра построена на фонетическом сходстве хоронима Дели и слова дали.

В заголовке Запарижская сечь (К, 20.8.2019) - о президентах на Лазурном берегу, обыгрывется астионим Париж, включенный в середину слова. Заголовок апеллирует к хорониму Запорожская Сечь.

Город Сухум обыгрывается в заголовке В Сухум остатке (К, 11.01.2020) - статья о роли Москвы в урегулировании конфликта, созданном по аналогии с выражением в сухом остатке. Заголовок построен на фонетическом сходстве названия города и прилагательного.

В заголовках издания «Коммерсантъ» было зафиксировано обыгрывание гидронима Керченский пролив: Керченский прогиб (К, 13.6.2019) - название статьи о санкциях США против PФ.

\section{Языковая игра с названиями произведений литературы и искусства}

Согласно многим существующим классификациям к именам собственным относят названия произведений литературы и искусства. Игровые заголовки, апеллирующие к литературным произведениям, частое явление на газетной полосе:

Притихший Дон (К, 13.4.2020) - статья о судоходных компаниях. Наблюдаем аллюзию на роман «Тихий Дон» М. А. Шолохова.

Над пропастью Алжир (К, 12.3. 2019) - статья о президенте Алжира. Наблюдается аллюзия на название книги Д. Сэлинджера «Над пропастью во ржи». Заголовок построен на фонетическом сходстве словосочетания во ржи и хоронима Алжир. 
Рим во время чумы (К, 12.3.2020) - о выставке Рафаэля. В заголовке прослеживается отсылка на трагедию А.С. Пушкина «Пир во время чумы». В заголовке отмечаем замену исходного компонента пир астионимом Рим.

Лебедь, рак и Яшин (К, 9.4.2019) - заголовок о праймеризе на пост мэра Москвы. В статье обыгрывается название басни И. Крылова «Лебедь, рак и щука». Отмечаем замену компонента щука антропонимом Яшин.

Вирус в тигровой шкуре (К, 17.4.2020) - статья о закрытии городов в Грузии. В заголовке автор обыгрывает название поэмы «Витязь в тигровой шкуре» Ш. Руставели, путем замены лексического компонента.

Азоты здесь тихие (К, 16.04.2020) - о спросе на удобрения. Заголовок апеллирует к названию повести Б. Васильева и одноименному фильму С. Ростоцкого «А зори здесь тихие».

Ночь перед торжеством (К, 10.12.2019) - об участниках нормандского формата. Заголовок обыгрывает название произведения Н.В. Гоголя «Ночь перед Рождеством».

Как закалялась соль (К, 13.12.2019) - о росте потребления соли; Как расплавлялась сталь (К, 14.11.2019) - о 35-летии фильма «Терминатор». Данные заголовки обыгрывают название романа Н. Островского «Как закалялась сталь».

Преступление и выживание (К, 27.9.2019) - о фильме «Боже, мой!». Заголовок содержит аллюзию на роман Ф.М. Достоевского «Преступление и наказание».

Горе от бума (К, 26.7.2019) - о фондовом рынке. Заглавие обыгрывает название комедии А.С. Грибоедова «Горе от ума».

Том с мезонином (К, 7.02.2019) - о музыкальной группе. Игровой заголовок отсылает к названию рассказа А.П. Чехова «Дом с мезонином».

По ком звонит оперштаб (К, 29.5.2020) - о жалобах на спам. В данном заголовке фиксируем отсылку к роману Э. Хемингуэя «По ком звонит колокол».

Танец маленьких этуалей (К, 5.3.2020) - о балете. В заголовке наблюдаем аллюзию на «Танец маленьких лебедей» из балета «Лебединое озеро» П. И. Чайковского.

Переход налоговой через Альпы (К, 15.2.2020) - о втором налогообложении. Заголовок обыгрывает название картины «Переход Суворова через Альпы» Василия Сурикова. Возможным импульсом для данного заголовка мог быть хрононим - Швейцарский поход А. Суворова.

«Югра» престолов (К, 25.5.2019) - статья о банках. В заголовке обыгрывается название книги и фильма «Игра престолов».

50 оттенков серы (К, 29.11.2019) - как повлияют на нефтяников, судовладельцев и энергетиков новые правила ІМО. Заглавие обыгрывает название романа Э. Джеймс «50 оттенков ceporo».

\section{Языковая игра с антропонимами}

Антропоцентрическая направленность современной лингвистики объясняет продуктивность имен собственных. Главными героями публицистического текста становятся антропонимы - имена и фамилии деятелей культуры, науки и спорта, сферы политики, экономики и т.п.

Проанализируем игровые заголовки с антропонимами в заглавиях исследуемого нами издания:

Дзюбо-дорого (К, 3.07.2019) - статья о представителях сборной России по футболу и их детских именах. В заголовке обыгрывается фамилия российского футболиста - Артема Дзюбы по 
аналогии с выражением любо-дорого.

Вирусь, куда ж несешься ты! (К, 1.2.2020) - статья о приходе коронавируса. В заголовке обыгрывается фонетическое сходство слова вирус и уменьшительно-ласкательной формы имени Вера (Веруся).

Крокодил генов (К, 6.1.2019) - о допинге в спорте. Заголовок обыгрывает имя персонажа популярного мультсериала «Чебурашка и Крокодил Гена».

Эрдоган, Эрдоган, Эрдоганище (К, 13.2.2020) - о президенте Турции. Заголовок построен по аналогии с выражением из сказки К. Чуковского «Таракан, таракан, тараканище!».

Ким-ким, откройся (К, 28.02.2019) - статья о встрече Дональда Трампа и Ким Чен Ына в Ханое. Заголовок обыгрывает заклинание из сказки “Али-Баба и сорок разбойников» - симсим, откройся. Игра строится на сходстве слова из заклинания сим и имени политического лидера Ким.

\section{Языковая игра с названиями кораблей}

Летучий шотландец (К, 7.05.2019) - заголовок статьи о дневниках сподвижника Петра Великого. Обыгрывается название легендарного корабля-призрака «Летучий голландец».

\section{Выводы}

Проанализировав игровые заголовки с именами собственными в публицистическом издании «Коммерсантъ» за 2019-2020 гг., можно утверждать, что самым многочисленным разрядом являются топонимы (в частности хоронимы) (30). Самыми частотными хоронимами для образования игровых заглавий были Китай, Иран, Ливия, Грузия, Украина, США. Доминантное положение топонимов на газетной полосе объясняется их функцией воспроизводить пространство и место событий.

Большое количество апелляций к литературным произведениям (18) указывает на литературоцентризм современного публицистического дискурса, начитанность авторов, престиж и актуальность как классической, так и современной литературы. Игры с именами политических деятелей указывают на либерализацию современного языка СМИ, а также на творческий потенциал авторов.

Самый востребованный прием создания игрового заголовка - подбор фонетически сходного компонента и замена им части прецедентного выражения. Часто применяемым приемом является окказиональное словообразование (по аналогии с уже существующим словом/выражением/текстом).

\section{Использованная литература/ References}

АПРЕСЯН, Ю.Д. (1995): Языковая аномалия и логическое противоречие. М.: Языки русской культуры, 1995. 767 c. Без ISBN.

БЕЛЕЦКИЙ, А.А. (1972): Лексикология и теория языкознания: (Ономастика). Киев: Издательство Киев. унта, 1972. 209 с. Без ISBN.

БУЛЫГИНА, Т.В.; ШМЕЛЕВ, А.Д. (1997): Языковая концептуализация мира (на материале рус. грамматики). М.: Языки русской культуры, 1997. 576 с. ISBN 5-88766-051.

БУРКОВА, Т.А. (2010): Функционально-стилистическое варьирование антропонимов в немецком языке: дисс. ... докт. филол. наук. Уфа, 2010. 428 с. 
ГРИДИНА, Т.А. (1996): Языковая игра: стереотип и творчество. Екатеринбург: УГПУ, 1996. 215 с. ISBN 57186-0102-Х.

ГРИДИНА, Т.А. (2002): Языковая игра как лингвокреативная деятельность. In Язык. Система. Личность. Формирование языковой личности в онтогенезе: сб. статей. Екатеринбург: УгПУ, 2002. с. 22 - 27.

МЕРзляковА, А.В. (2015): Семантический потенциал топонимов современного французского языка: дисс. ... канд. фил. наук. Нижний Новгород: НГлУ им. Н.А. Добролюбова, 2015. 177 с.

НАХИМОВА, Е.А. (2011): Прецедентные онимы в современной российской массовой коммуникации: теория и методика когнитивно-дискурсивного исследования (Монография), Екатеринбург: УГПУ, 2011. 276 c. ISBN 978-5-7186-0459-7.

НОРМАН, Б.Ю. (1987): Язык: знакомый незнакомец. Минск: Вышэйшая школа, 1987. 220 с. Без ISBN.

ПУШКАРЕВА, И.А. (2012): Категория пространства в художественно публицистическом тексте (на метериале городской газеты). In Вестник Челябинского государственного университета. Сер. Филология. Искусствоведение. Вып. 64. 2012. № 6 (260), с. 104-109.

РУССКАЯ ГРАММАТИКА (1980-1982): в 2 т. Акад. наук СССР, Ин-т рус. яз.; (редкол.: д. филол. н. Н. Ю. Шведова (гл. ред.) и др.). Москва : Наука, 1982. 783 с. Без ISBN.

САННИкОВ, В. 3. (1999): Русский язык в зеркале языковой игры. М.: Языки русской культуры, 1999. 542 с. ISBN: 5-7859-0077-7.

СКОВОРОДНИКОВ, А.П. (2010): Игра как прием текстопорождения. Коллективная монография. Красноярск: СФУ, 2010. 341 с. ISBN 978-5-7638-2030-0.

СУПЕРАНСКАЯ, А.В. (1974): Общая теория имени собственного. М. : Наука, 1974. 365 с. Без ISBN.

СУПЕРАНСКАЯ, А.В. (1984): Что такое топонимика: Из истории географических названий. М. : Наука, 1984. 182 с. Без ISBN.

СУПЕРАНСКАЯ, А.В. (2012): Общая теория имени собственного. 4-е изд. М.: Либроком, 2012. 370 с. ISBN 978-5-397-03085-4.

УРАЗМЕТОВА, А.В. (2006): Лингвокультурологический аспект изучения топонимов в составе фразеологических единиц (на метериале английского и французского языков): дисс. ... канд. филол. наук. Уфа: БГУ, 2006. 196 с.

ФЛЕЙШЕР, Е.А. (2014): Основы прецедентности имени собственного : дисс. ... канд. филол. наук. СПб: С.Петерб. гос. ун-т, 2014. 164 с.

ДАННАЯ СТАТЬЯ ПОДГОТОВЛЕНА В РАMКАХ ПРОЕКTA KEGA С̌. 021UCM-4/2020 S NÁZVOM TVORBA UČEBNÍC PRE RUSKOSLOVENSKÉ SEKCIE BILINGVÁLNYCH A SLOVANSKÝCH GYMNÁZIÍ.

\section{Профиль автора:}

Ольга Евгеньевна Ермачкова, старший преподаватель, к.ф.н.

Научные интересы: динамические процессы в современном русском языке, лингвокультурология e-mail: olga.iermachkova@ucm.sk

Место работы: Университет Св. Кирилла и Мефодия в Трнаве, Трнава, пл. Й. Герду 2, 917 01, Словакия

\section{Author's profile:}

Mgr. Olga lermachkova, PhD.

Research interests: dynamic processes in the modern Russian language, linguoculturology

e-mail: olga.iermachkova@ucm.sk

Place of work: University of Ss. Cyril and Methodius in Trnava, J. Herdu 2, 917 01, Trnava, Slovakia 